\title{
Coronary artery bypass surgery in smokers
}

Morris et al (page 557) have confirmed, yet again, the very much higher relative risk of ischaemic heart disease in current smokers than in never smokers, with intermediate rates in those men who were ex-smokers at baseline. ${ }^{1}$ This follow up study of British men found that similar proportions of smokers and ex-smokers were referred to a cardiologist and similar proportions reported undergoing angiography. However, only $9 \%$ of those who developed the disease who were smokers at baseline had coronary artery bypass surgery compared with $16 \%$ of ex-smokers and $18 \%$ of never smokers.

Some of the differences in selection for surgery are likely to reflect differences in survival during follow up in continuing, ex, and never smokers. On the basis of operations per 1000 per year, smokers at baseline had slightly higher annual rates of surgery than never smokers, with highest rates in those who were ex-smokers.

\section{Discrimination against smokers?}

The findings of Morris et al on coronary artery bypass surgery rates in smokers accord with those of other studies. One study found longer waiting times for cororary artery surgery in smokers compared with never or exsmokers. ${ }^{2}$ A study in the United States found that smoking status was unlikely to affect decisions about treating conditions that were not related to smoking, such as referral for hernia repair or haemodialysis. ${ }^{3}$ But physicians were less likely to refer smokers for coronary artery bypass surgery or peripheral arterial surgery. Reasons cited included reduced efficacy and greater risk of treatment in smokers. Other reasons included "reduced entitlement" of smokers to complex treatment for smoking-related diseases. Treatment was also withheld as a bargaining tool to encourage smokers to quit.

Given the evidence of different selection rates for smokers for coronary artery bypass surgery, are these differences in accordance with evidence of best practice? Is the difference in treatment that depends on smoking status ethically acceptable? Do the different selection rates for surgery represent discrimination against smokers?

\section{Risks in smokers}

There is substantial evidence, including that presented in the paper by Morris $e t$ al, that stopping smoking reduces the risk of further coronary events in patients with coronary artery disease. There is evidence that smokers who are admitted to hospital with a myocardial infarction have a better prognosis than non-smokers. ${ }^{4}$ This may be explained by the lower prevalence of other risk factors in smokers or by the relative ease with which smoking as a risk factor may be removed from the risk equation.

Smokers have a larger reduction in mortality after thrombolytic therapy than non-smokers. ${ }^{5}$ Studies of coagulation factors and quantitative coronary angiographic analysis suggest that the mechanism of infarction in smokers results from thrombosis of a less critical atherosclerotic lesion than in non-smokers.

\section{Indications for surgery}

An overview of randomised controlled trials of medical treatment compared with coronary artery bypass surgery found significantly lower mortality among those randomised to surgery. ${ }^{6}$ The 2649 patients, mainly men under the age of 60 , were randomised between 1972 and 1984. Perioperative mortality was $3 \cdot 2 \%$ among those who underwent surgery as part of trial protocol. It is likely that mortality would be lower nowadays but it must be recognised that medical treatment too has improved. ${ }^{7}$

The overview by Yusuf $e t$ al found important reductions in mortality in those with left main artery disease and in those with disease in three vessels. ${ }^{6}$ Benefit was least in those with one or two vessel disease. When a number of risk characteristics were used to devise two different risk scores to compare mortality benefit at five years, the two thirds of patients in the middle and highest risk groups had significantly higher survivorship after five years with surgery; there was no evidence of benefit in the one third of patients with the lowest risk scores.

\section{Outcomes in smokers}

The overview of trials found that outcomes were not significantly different when analysed by smoking status at entry. ${ }^{6}$ However, some studies have found evidence of greater risk associated with surgery in smokers compared with non-smokers, including in women and the elderly. ${ }^{89}$

After ten years of follow up, the Coronary Artery Surgery Study could analyse outcome by smoking status at randomisation and by whether or not the patient had quit smoking within six months. ${ }^{10}$ Survival at ten years was best in smokers who were randomised to surgery and who quit smoking within six months (84\%) and worst in those randomised to surgery who did not quit $(68 \%)$; survival was intermediate in those randomised to medical treatment who had quit $(75 \%)$ or who had not quit $(71 \%)$.

The European Coronary Surgery Study has been quoted as showing that smokers and non-smokers benefit equally from surgery. ${ }^{11}$ Patients were entered into this trial between 1973 and 1976; there were no significant differences in survival in those with two vessel disease in the medical or surgical arms of the trial, and those who had surgery were significantly more likely to have quit smoking at follow up at one year though not at later follow up checks. ${ }^{12}$ It does not seem appropriate to conclude on the basis of this trial that smokers being assessed in the $1990 \mathrm{~s}$ 
are likely to benefit from surgery to the same extent as non-smokers.

\section{Risks and benefits}

The evidence at present suggests that the benefits of surgery are likely to outweigh any increased risks associated with current smoking status in patients who have left main artery disease and in those with disease in three vessels. When there is disease in one or two vessels it would therefore be appropriate to assess the risks and benefits of surgery and of other treatment options in each patient. It is worth remembering that "small risks may outweigh small benefits". ${ }^{13}$

All patients should be encouraged to stop smoking. The most effective support strategies should be used to help patients stop smoking. ${ }^{14}$

Medical treatment should be chosen only if it is judged to be the most appropriate treatment for the patient at that time; this choice should not be communicated as an irrevocable decision. It may be counterproductive to recommend surgery but then indicate that this is contingent on the patient's stopping smoking.

In life-threatening situations it would be unethical to withhold treatment because of the patient's smoking history. Neither should clinicians make value judgements as to who is deserving of treatment on the basis of social or behavioural characteristics. Allocation of resources within a clinical service should be based on the evidence of likely benefits and risks.

\section{Future research}

The available trial data do not relate to the majority of patients in whom decisions are being made about whether or not they will benefit from coronary artery bypass surgery. Current trials seem to concentrate on comparing surgery with angioplasty. ${ }^{15}$ Given the benefits of pharmacological treatment and of advice about lifestyle changes, is it not time to include an arm which evaluates intensive non-interventional medical treatment?

There is little overlap between the characteristics used to stratify risk to facilitate decisions about the appropriateness of surgical intervention or the treatment of chronic stable angina ${ }^{89}$ and the risk characteristics proposed for secondary prevention. ${ }^{16}$ The next major step forward seems to be for surgeons, cardiologists, and prevention/ rehabilitation specialists to pool their expertise. Clinicians do not treat coronary arteries or smokers but whole individuals. They need risk stratification techniques that take into account not just symptoms and cardiac function but other risk factors for atherosclerosis and the extent to which risk can be ameliorated by different treatments. EMER SHELLEY

Department of Epidemiology and Preventive Medicine, Royal College of Surgeons in Ireland,

Mercer Street,

Dublin 2, Ireland

1 Morris RW, McCallum AK, Walker M, Whincup PH, Ebrahim S, Shaper AG. Cigarette smoking in British men and selection for coronary artery bypass surgery. Heart 1996;75:557-62.

2 Kee F, Gaffney B, Currie S, O'Reilly D. Access to coronary catheterisation: fair shares for all? $\mathrm{Br}$ Med $\mathcal{F}$ 1993;307:1305-7.

3 Mogielnicki RP, Bell J, Fowler FJ. The influence of patient smoking status on therapeutic decisions. F Gen Intern Med 1992;7:165-9.

4 Fresco C. Conventional risk factors reconsidered in patients with acute myocardial infarction. $f$ Cardiovasc Risk 1994;1:290-4.
mato

5 Grines CL, Topol EJ, O'Neill WW, George BS, Kerriakas D, Phillips HR, et al. Effect of cigarette smoking on outcome after thrombolytic therapy
foritips et al. Effect of cigarette smoking on outcome after thro
for myocardial infarction. Circulation 1995;91:298-303.

6 Yusuf S, Zucker D, Peduzzi P, et al. Effect of coronary artery bypass graft surgery on survival: overview of 10 -year results from randomised trials by the Coronary Artery Bypass Graft Surgery Trialists Collaboration. Lancet the Coronary Arte

7 Gorlin R. Treatment of chronic stable angina pectoris. Am $f$ Cardiol 1992;70:26G-31G.

8 Ramstrom J, Lund O, Cadavid E, Thuren J, Oxelbark S, Hanze A. Multiarterial coronary artery bypass grafting with special reference to small vessel disease and results in women. Eur Heart f 1993;14:634-9.

$9 \mathrm{He} \mathrm{GW,} \mathrm{Acuff} \mathrm{TE,} \mathrm{Ryan} \mathrm{WH,} \mathrm{Mack} \mathrm{MJ.} \mathrm{Risk} \mathrm{factors} \mathrm{for} \mathrm{operative} \mathrm{mortal-}$ ity in elderly patients undergoing internal mammary artery grafting. Ann Thorac Surg 1994;57:1453-60.

10 Cavender JB, Rogers WJ, Fisher LD, Gersh BJ, Coggin CJ, Myers WO. Effects of smoking on survival and morbidity in patients randomised to medical or surgical therapy in the Coronary Artery Surgery Study (CASS): 10-year follow-up. CASS Investigators. $f \mathrm{Am}$ Coll Cardiol 1992;20:287-94.

11 Julian DG. Smoking and coronary artery bypass surgery. Br Heart $\mathcal{f} 1994$ 72:9-11.

12 European Coronary Surgery Group. Long-term results of prospective randomised study of coronary artery bypass surgery in stable angina pectoris. Lancet 1982;ii: $1173-80$.

13 Davey Smith G, Egger $M$. Who benefits from medical interventions? Treating low risk patients can be a high risk strategy. $B r M e d ~ \mathcal{F} 1994$; 308:72-4.

14 Killoran A (ed). Giving up smoking: does patient education work? Summary. London: Health Education Authority, 1993.

15 Pocock S, Henderson RA, Rickards AF, Hampton JR, King SB, Hamm $\mathrm{CW}$, et al. Meta-analysis of randomised trials comparing coronary angioCW, et al. Meta-analysis of randomised trials comparin

16 Pyorala K, De Backer G, Graham I, Poole-Wilson P, Wood D on behalf of Pyorala K, De Backer G, Graham I, Poole-Wilson P, Wood D on behalf of
the Task Force of the European Society of Cardiology, European the Task Force of the European Society of Cardiology, European Atherosclerosis Society and European Society of Hypertension. Preven-
tion of coronary heart disease in clinical practice. Eur Heart $₹$ 1994;15: $1300-31$. 